\title{
Serotonin-Dopamine Interactions in the Control of Conditioned Reinforcement and Motor Behavior
}

\author{
Deanna M. Sasaki-Adams, B.S., and Ann E. Kelley, Ph.D.
}

These studies addressed the question of serotonin (5-HT)dopamine (DA) interactions with regard to reward-related behavior and motor activity in rats. The first experiment evaluated the effect of chronic treatment with fluoxetine ( 7 $\mathrm{mg} / \mathrm{kg} /$ day), a serotonin-selective reuptake inhibitor, and buproprion (15 mg/kg/day), a dopamine reuptake inhibitor, on responding for conditioned reinforcement (CR). Chronic fluoxetine, but not buproprion, enhanced CR responding, and also potentiated cocaine-induced increases in $C R$ responding. In the second experiment, animals received intra-accumbens infusions of either 5-HT (0, 1, 5, and 10 $\mu g)$ or $D A(10,20 \mu g)$ prior to the conditioned reinforcement test. Dopamine, but not 5-HT, selectively facilitated $C R$ responding, although 5-HT non-specifically increased responding as well. In the third and fourth experiments, it was demonstrated that intra-accumbens 5-HT causes increased motor activity, which was partially blocked by DA antagonists. The results suggest that chronically increased levels of 5-HT may facilitate rewardrelated behavior, but most likely via indirect modulatory mechanisms affecting general arousal and motor tone.

[Neuropsychopharmacology 25:440-452, 2001] (C) 2001 American College of Neuropsychopharmacology. Published by Elsevier Science Inc.
KEY WORDS: Nucleus accumbens; Fluoxetine; Buproprion; Cocaine; Conditioned reinforcement; Serotonin; Dopamine; Locomotor activity

The dopaminergic and serotonergic neurotransmitter systems are thought to play a critical role in the regulation of emotion and mood, and have been implicated in a spectrum of neuropsychiatric disorders. Psychotropic drugs affecting dopaminergic or serotonergic systems have been used to treat such disorders as depression, bipolar disorder, schizophrenia, eating disorders, obsessive compulsive disorder, and autism and have also been used to alleviate motor dysfunction associated with Tourette's syndrome, Parkinson's disease, and

From the Department of Psychiatry, University of WisconsinMadison Medical School, Madison, WI.

Address correspondence to: Ann E. Kelley, Ph.D., Department of Psychiatry, University of Wisconsin-Madison Medical School, 6001 Research Park Boulevard, Madison, WI 53719.

Received 8 November 1999; revised 5 November 2000; accepted 4 December 2000. self-injurious behavior. Since both these transmitter systems appear to play such a critical role in mental functions, there has been a considerable amount of interest in their potential interactions.

The nucleus accumbens, which has been implicated in reward and motivation, is one brain region where such an interaction may take place. There are high levels of dopamine (DA), dopamine receptors, serotonin (5-HT), and serotonin receptors in this forebrain region (Beal and Martin 1985; Bonaventure et al. 1997; Bouyer et al. 1984; Eberle-Wang et al. 1997; Joyce and Marshall 1987; Kilpatrick et al. 1987; Phelix and Broderick 1995; Van Bockstaele et al. 1993; Van Bockstaele and Pickel 1993). The classical role of dopamine in the nucleus accumbens has been attributed to regulating motivation and reward-related behavior (Robbins and Everitt 1996; Schultz 1997; Wise and Rompré 1989). For example, drugs of abuse, such as cocaine and amphetamine, are believed to exert their euphoric effects primarily via activating the dopamine system (Di Chiara and Imperato 
1988; Koob and Bloom 1988). In contrast to the substantial body of research on dopamine in the nucleus accumbens, there has been comparatively little attention given to the role of serotonin and serotonin-dopamine interactions in the nucleus accumbens.

There are a number of reasons why further understanding of dopamine-serotonin interactions would be useful. Although depression undoubtedly involves a complex dysregulation of many transmitter and neuroendocrine systems, a majority of drugs used to treat depression affects the serotonin system. Serotoninselective re-uptake inhibitors (SSRIs) such as fluoxetine enhance synaptic levels of serotonin (5-HT), and are generally quite effective in ameliorating the symptoms of depression. Thus, one widely held hypothesis is that dysfunction in serotonergic neurons and their targets may underlie depressive symptomatology (van Praag et al. 1987). Although serotonergic systems are most often implicated in mood, dopaminergic systems are traditionally associated with reward and appetitive motivation. Since a hallmark of depression is diminished ability to experience pleasure, it is logical to propose that dopaminergic effects may be involved in the antidepressant effects of SSRIs. Such a putative effect would likely involve serotonin-dopamine interactions. Moreover, although less commonly prescribed, drugs enhancing dopaminergic function such as buproprion also are effective antidepressants (Ascher et al. 1995).

There is ample evidence for serotonergic influences on dopamine function. Although several early studies indicated an inhibitory role of 5-HT on dopaminergic activity (Korsgaard et al. 1985; Pycock et al. 1978; Warbritton et al. 1978), much recent evidence suggests a facilitatory effect on DA. For example, a number of in vivo microdialysis studies have clearly shown that exposure of the striatum or nucleus accumbens to serotonin results in increased release of dopamine (Benloucif and Galloway 1991; De Deurwaerdere et al. 1996; Hallbus et al. 1997; Parsons and Justice 1993; Yadid et al. 1994; Yoshimoto et al. 1996), although the mechanism underlying such an enhancement is unclear. Other methodological approaches have also shown such a relationship (Blandina et al. 1988; Jacocks and Cox 1992; Nurse et al. 1988; Yi et al. 1991).

There has also been much interest in these interactions with regard to the role of serotonin function in cocaine's psychomotor stimulating and reinforcing effects (Broderick and Phelix 1997; Cunningham et al. 1996; Parsons et al. 1995; Walsh and Cunningham 1997). For example, although SSRIs do not substitute for cocaine in drug discrimination tests, they do potentiate the stimulus effects of cocaine (Cunningham and Callahan 1991; Kleven and Koek 1998). Although many of these studies tend to suggest a potentiating influence of serotonergic drugs on dopaminergic tone, the picture is complicated by the existence of multiple subtypes of
5-HT receptors. For example, $5-\mathrm{HT}_{1 \mathrm{~B}}$ and $5-\mathrm{HT}_{3}$ agonists tend to facilitate dopaminergic effects (De Deurwaerdere et al. 1998; Parsons et al. 1996), whereas 5$\mathrm{HT}_{2 \mathrm{C}}$ agonists have been reported to inhibit such effects (Walsh and Cunningham 1997).

In the present work, we have conducted several experiments examining the role of 5-HT and DA in conditioned reinforcement and locomotor activity in rats. The first experiment sought to examine the effect of chronic treatment with fluoxetine and buproprion in the conditioned reinforcement paradigm. This paradigm measures an animal's operant responding for a stimulus that has secondary reinforcing properties by virtue of having been previously associated with food reward (Robbins 1978). Clinical depression often manifests itself as anhedonia, in which interest and motivation for normally pleasurable stimuli is compromised. Although the conditioned reinforcement paradigm is not an animal model of depression, it is a valid test of an animal's responsivity to a rewarding stimulus. Further, this experiment examined the effects of chronic antidepressant treatment on the potentiating effect of cocaine in this paradigm. The second experiment evaluated the effect of direct intra-accumbens infusion of 5-HT and dopamine in the conditioned reinforcement paradigm. The third experiment explored the role of 5-HT in the nucleus accumbens with regard to locomotor activity. The final experiment investigated the influence of dopamine D1 and D2 antagonists on the motor activation elicited by infusion of 5-HT into the nucleus accumbens.

\section{METHODS}

\section{Subjects}

The animals used in these experiments were treated in accordance with the Guide for the Care and Use of Laboratory Animals as adopted and promulgated by the National Institutes of Health. A total of 51 male Sprague-Dawley rats weighing 250-300 g were housed two per clear, plastic cage. They were maintained on a 12 hour light/dark schedule with lights on at $0700 \mathrm{~h}$. The animals were handled upon arrival and consistently during the experiment in order to minimize the effects of stress induced by handling. In Experiments 1 and 2, animals were maintained on a restricted feeding schedule; in Experiments 3 and 4, they were maintained ad libitum. In Experiment 1, when it became apparent that fluoxetine-treated rats were losing weight more than the other groups, the rats were given extra food in an attempt to maintain their weight.

\section{Surgery}

For Experiments 2-4, rats were subjected to stereotaxic implantation of bilateral chronic indwelling cannulae 
(23 gauge; $0.063 \mathrm{~cm}$ ). They were anesthetized using 0.6 $\mathrm{mg} / \mathrm{kg}$ of a Ketamine/xylazine mixture and then placed in a stereotaxic apparatus with the incisor bar placed $5 \mathrm{~mm}$ above interaural zero. The guides were implanted to place their tips $2.5 \mathrm{~mm}$ above the injection target according to coordinates from the atlas of Paxinos and Watson (1998). Anterior-posterior measurement (in $\mathrm{mm}$ ) was +1.4 from bregma, lateral-medial \pm 1.7 from midline, and dorsal-ventral -5.5 from the surface of the skull. The cannulae were fastened to the skull using stainless steel mounting screws and dental cement. Wire stylets were placed in the cannulae to prevent occlusion. The animals were allowed a week of recovery following the surgery before behavioral testing.

\section{Microinfusion Procedure}

Initially, rats received a mock injection with a $10 \mathrm{~mm}$ injector placed into the guide cannulae. Two days prior to the first test session, each of them received a vehicle infusion into the nucleus accumbens. The vehicle employed was isotonic saline.

For the infusion procedure, the wire stylets were removed and bilateral stainless steel injector cannulae (30 gauge; $0.03 \mathrm{~cm}$ ), attached via polyethylene tubing to two $10 \mathrm{ml}$ Hamilton syringes mounted on a microinfusion pump (Harvard Apparatus, So. Natick, MA), were lowered through the guides to the accumbens $(2.5 \mathrm{~mm}$ below the tip of the guide to a final $\mathrm{D}-\mathrm{V}$ coordinate of -8.0 from skull). Test drug or vehicle was delivered bilaterally at a rate of $0.32 \mu \mathrm{l} / \mathrm{min}$ for a total infusion volume of $1.0 \mu \mathrm{l}$ per side. A diffusion time of $1 \mathrm{~min}$ was allowed before removal of the injector and replacement of the stylets.

\section{Drugs}

The drugs used in these experiments included fluoxetine hydrochloride, buproprion hydrochloride, pargyline hydrochloride, dopamine hydrochloride, the D1 dopamine receptor antagonist $\mathrm{R}(+)-\mathrm{SCH}-23390$ hydrochloride, the D2 dopamine receptor antagonist, S(-)-racloprideL-tartrate, and ketamine hydrochloride/xylazine hydrochloride solution, which were all purchased from RBI, Natick, MA, and stored appropriately. 5-Hydroxytryptamine hydrochloride was obtained from Sigma-Aldrich (St. Louis, MO). Cocaine hydrochloride was provided by the National Institute on Drug Abuse.

\section{Histological Analysis}

Following completion of the experiments, each animal was deeply anaesthetized with $0.6 \mathrm{ml}$ sodium pentobarbital and perfused transcardially with $0.9 \%$ saline followed by $10 \%$ formalin. Brains were removed and stored in $10 \%$ formalin. Before cutting, brains were soaked for 24 hours in a $20 \%$ sucrose-formalin solution. They were then frozen and cut in the cryostat into 60 $\mathrm{mm}$ sections. These sections were stained with cresyl violet and analyzed using a light microscope to determine the location of the cannulae tracks. Photomicrographs from representative animals are shown in Figure 1.

\section{Behavioral Testing}

Conditioned Reinforcement Paradigm. Five operant chambers (Coulbourn Instruments, Allentown, PA) were used for this experiment. The chambers were all soundproof and were initially equipped with a pellet dispenser, houselight, and a speaker. During the testing phase, two levers were added to the chamber and the pellet dispenser was blocked with cotton to prevent pellets from dropping into the food hopper. A computer system (Paul Fray, Cambridge, U.K.) controlled the activities of the operant chambers and was used for data collection.
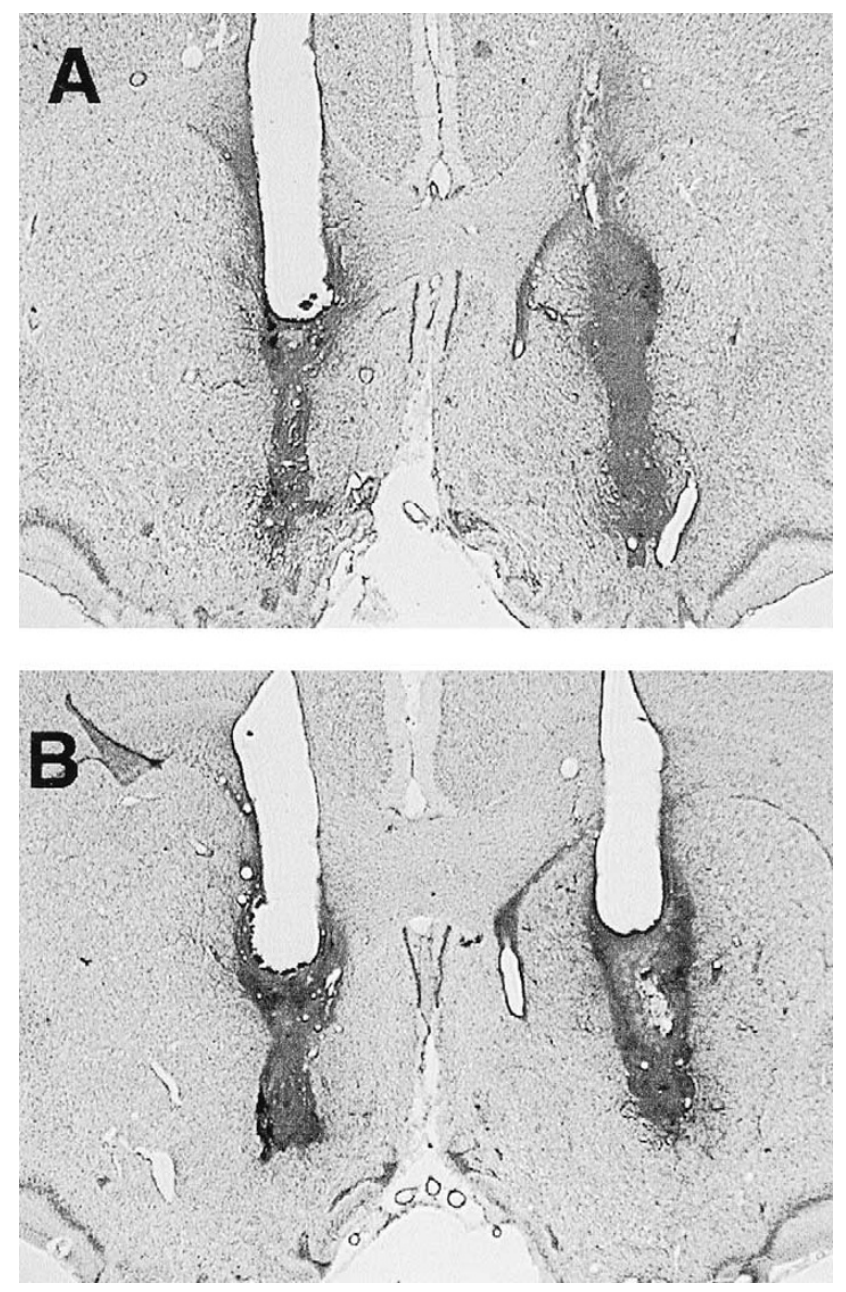

Figure 1. Histological representations of cannula tracks in the nucleus accumbens, from Experiment 2. (A) and (B) show coronal sections from two different animals. 
The animals were maintained at approximately $85 \%$ of free-feeding weight. They were first habituated to the chambers for two days, during which several sugar pellets ( $45 \mathrm{mg}$; Bioserv) were placed in the food magazine. Following habituation, the rats were subjected to a classical conditioning paradigm (the training phase) in which the delivery of a sugar pellet was always preceded by presentation of a compound stimulus. The stimulus was comprised of house lights off, red panel light on, and the click of the food dispenser. The stimulus was presented just prior to pellet delivery. The initial session was a random-time 10 -sec reinforcement schedule. Animals were trained not to put their head in the food magazine prematurely by introducing a 3-sec delay in the next pellet delivery if they responded outside of stimulus presentation. The training progressed on an increasing random time schedule until a randomtime 45-sec reinforcement schedule was achieved, with 30 pairings per session.

During the test phase of the experiment, two levers were installed in the operant chambers and the pellet dispenser was blocked. Pressing the "correct" lever resulted in the presentation of the compound stimulus but no pellets. Responses on the "incorrect" lever had no consequences. Each of the rats was assigned a lever to correspond to the correct lever and these assignments were maintained through the course of the experiment. In a preliminary session, the rats were placed in the chambers until they pressed the correct lever 10 times. On the following day the first test session occurred, during which data was recorded. The number of correct and incorrect responses was recorded in addition to the number of nose pokes into the food hopper. The test sessions lasted $30 \mathrm{~min}$, and occurred every other day.

\section{Activity Cages}

Activity testing was performed in clear polycarbonate cages, resembling the animals' home cages, and measuring $47 \mathrm{~cm} \times 26 \mathrm{~cm} \times 20 \mathrm{~cm}$ with raised wire grid floors. Two infrared photocell beams with emitters and detectors were located along the horizontal axis of the cages to record motor activity (San Diego Instruments).

Locomotor activity was defined as movement from one end of the cage to the other, (beam breaks preceded by an adjacent beam break). Rearing activity was recorded as the total number of photocell beam breaks that occurred near the top of the cages. Total activity was defined as the sum of all horizontal photocell beam breaks. In experiments utilizing this paradigm, the animals were habituated to the cages for 2 hours on two separate days, in order to adapt them to the environment. During the test phase, rats were tested for 120 min with counts being recorded at 10-min intervals. All testing was done between 1200 and 1600 hours.

\section{Experimental Procedure}

Experiment 1: Responding for Conditioned Reinforcement in Rats Chronically Treated with Fluoxetine or Buproprion. In this experiment, three groups of rats $(n=8 /$ group) were given daily injections intra-peritoneally for 19 days. These were maintained at approximately $85 \%$ of free-feeding weight. The three groups were treated daily with either $7 \mathrm{mg} / \mathrm{kg}$ of fluoxetine (i.p., in the afternoons following food administration), $7.5 \mathrm{mg} / \mathrm{kg}$ of buproprion (twice daily), or $0.3 \mathrm{ml}$ of isotonic saline as a vehicle into the control group (once daily).

During this treatment regimen, the rats underwent classical conditioning training in the operant chambers as described above for 10 days. For the first test session, animals were tested for lever-pressing under baseline conditions (no cocaine). During subsequent test sessions, animals received either 0,10 , or $25 \mathrm{mg} / \mathrm{kg}$ cocaine, i.p., counterbalanced for order $10 \mathrm{~min}$ before being placed in the chambers. All animals received each treatment. On test days, the animals always received their chronic treatment injection after the test. All animals were weighed daily, as there is evidence that chronic antidepressant treatment can cause weight loss.

Experiment 2: The Effect of Intra-Accumbens Dopamine and Serotonin in the Conditioned Reinforcement Test. In this experiment, animals $(n=10)$ were trained in the CR procedure as described above. On test days, seroto$\operatorname{nin}(0,1,5$, and $10 \mu \mathrm{g} / \mu \mathrm{l})$ was infused into the nucleus accumbens in a counterbalanced design, and animals were placed immediately in the chambers for data recording. Following these treatments, two further injections of dopamine $(5,10 \mu \mathrm{g} / \mu \mathrm{l})$ were administered on separate test days. Thus, in this within-subjects design each animal received a total of six microinjections. All rats (including vehicle-injected) also received a pretreatment (30 min prior to intracerebral treatment) of the MAO inhibitor pargyline $(25 \mathrm{mg} / \mathrm{kg}$ ) each test day in order to delay the catabolism of monoamines.

Experiment 3: The Effect of Intra-Accumbens Injections of Serotonin on General Motor Activity. In this study, rats $(n=9)$ received microinjections of $0,1,5$, and $10 \mu \mathrm{g}$ serotonin infused into the nucleus accumbens, following an i.p. pretreatment of pargyline as described above. In this within-subjects design, treatments were given on separate test days every other day, with order of dose counterbalanced. Animals were placed in activity cages for $120 \mathrm{~min}$ and behavior was recorded.

Experiment 4: Influence of D1 and D2 Receptor Antagonists on Motor Response to Intra-Accumbens Serotonin. Cannulated rats $(n=9)$ received an intra-accumbens infusion of serotonin $(5 \mu \mathrm{g})$ combined with an i.p. injection of vehicle, $0.1 \mathrm{mg} / \mathrm{kg} \mathrm{SCH} 23390$ or $1.0 \mathrm{mg} / \mathrm{kg}$ raclopride, in a within-subjects design. These doses were chosen on the basis of their ability to clearly block 


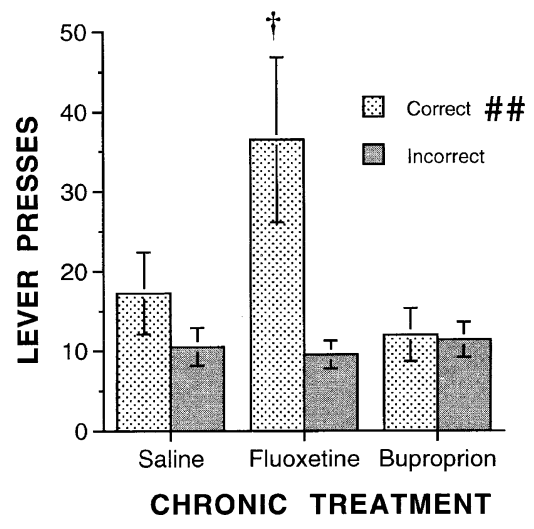

Figure 2. Baseline lever-pressing in the conditioned reinforcement test in rats chronically treated with antidepressants, before cocaine was given (see text for details of treatment). Correct responses are those responses on lever producing the conditioned reinforcer (light/click that had been associated with food); incorrect responding has no consequences. ${ }^{\dagger} p<$ .05 , group $\times$ lever interaction; \#\# $p<.01$, lever effect.

DA-mediated behavior (Chu and Kelley 1992; Yeghiayan and Kelley 1995). Rats also received an intra-accumbens injection of vehicle (saline) in combination with i.p. saline. Thus, each animal received all four treatments in a counterbalanced order, with test days separated by at least two days. They also received the pargyline i.p. treatment 30 min before intra-accumbens treatment, and the DA antagonist treatment $15 \mathrm{~min}$ prior to the accumbens treatment.

\section{Data Analysis}

Data were analyzed using the SuperAnova software program (Abacus Concepts) for the Macintosh. For Experiment 1, a repeated measures, 3-factor analysis of variance (ANOVA) was used, with chronic treatment group as the between-subjects factor. The within sub- jects factors were dose of cocaine and lever. A 2-factor between-within ANOVA was also carried out on the weights of the rats from day 11 to day 18 of chronic treatment. For Experiment 2, a repeated measures 2-factor design (dose and lever) was used. (The 5-HT and dopamine data were analyzed separately.) For Experiment 3, a repeated measures 2-factor design (dose and time) was employed, for each of the behavioral categories recorded. For Experiment 4, a repeated measures 2-factor design was also employed (treatment and time).

\section{RESULTS}

\section{Experiment 1: Responding for Conditioned Reinforcement in Rats Chronically Treated with Fluoxetine or Buproprion}

Analysis for baseline responding during the first test session (no cocaine injection given) revealed a significant group $\times$ lever interaction $(\mathrm{F}[2,21]=4.61, p<.02]$, as well as an overall lever effect for all the animals $(\mathrm{F}[1,21]=9.5, p<.01)$. Figure 2 shows that fluoxetinetreated animals showed a marked preference for the CR (rewarded) lever compared with either the saline or buproprion groups. Analysis of simple main effects indicated that this overall effect was due to a significant interaction between the saline and fluoxetine groups $(\mathrm{F}[1,21]=4.96, p<.05)$, as well as the buproprion and fluoxetine groups $(\mathrm{F}[1,21]=8.4, p<.01)$.

The buproprion group was no different from the chronic saline group. The effect of cocaine in these animals is shown in Figure 3. It is well established that cocaine and other psychostimulants have a potentiating effect on lever-pressing for a conditioned reinforcer (Chu and Kelley 1992; Kelley and Delfs 1991; Robbins 1978). It can be observed from the figure that cocaine generally enhanced CR responding in all groups. Analysis of variance indicated an overall effect of cocaine

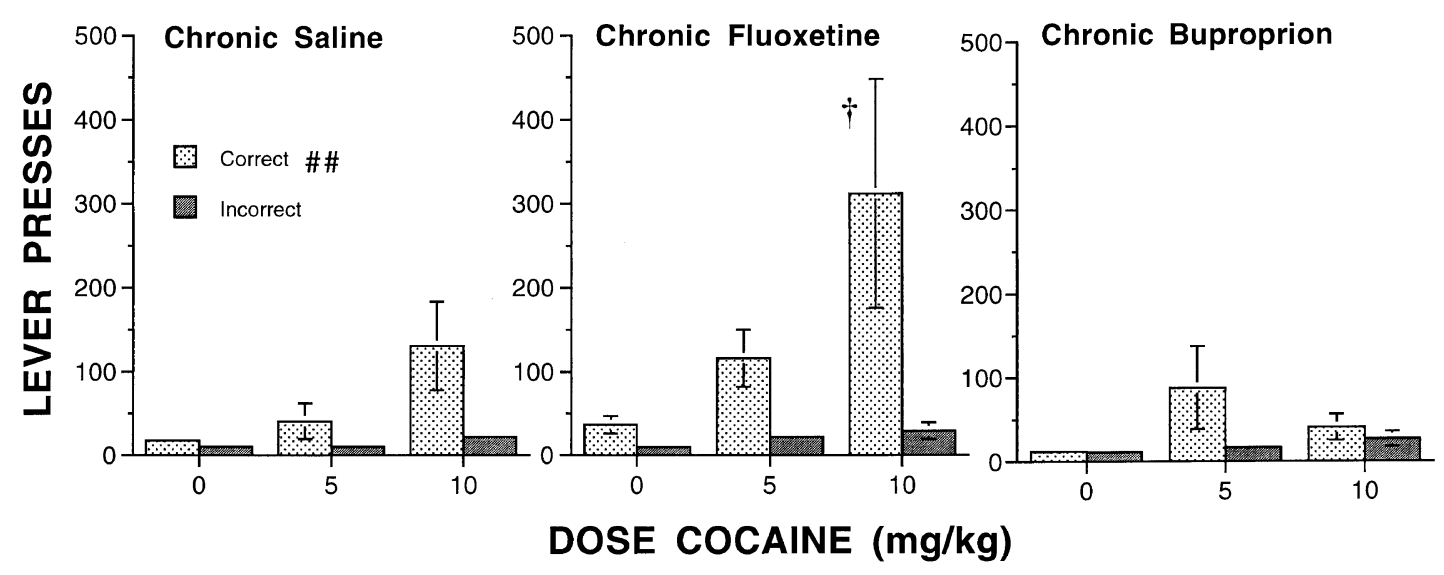

Figure 3. Effect of systemically administered cocaine in the conditioned reinforcement test in animals treated chronically with antidepressants (see text for details of treatment). ${ }^{\dagger} p<.05$, dose $\times$ treatment $\times$ lever interaction. \#\# $p<.01$, lever effect. 


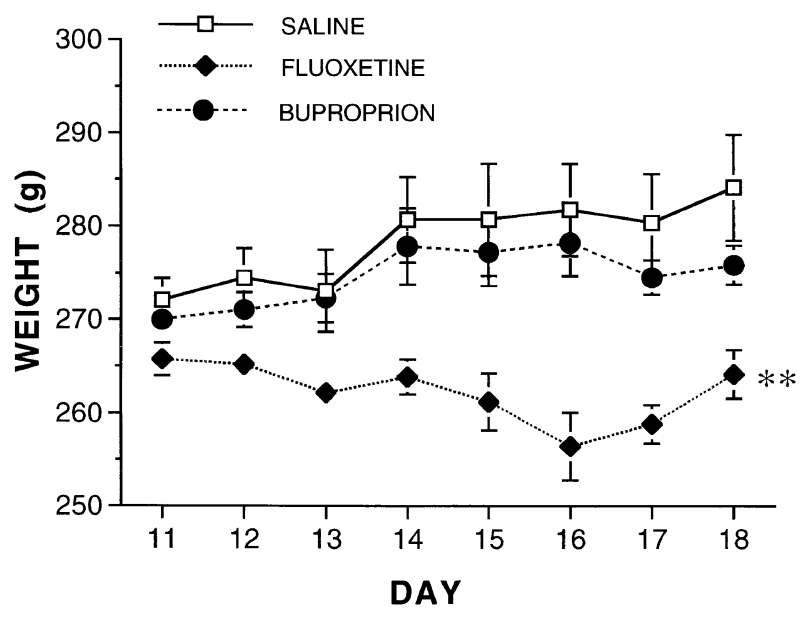

Figure 4. Weight in grams for the three chronic treatment groups in Experiment 1. Chronically-treated fluoxetine rats had significantly lower weights. ${ }^{* *} p<.01$, group effect.

dose $(\mathrm{F}[2,42]=7.3, p<.002)$, a dose $\times$ lever interaction $(\mathrm{F}[2,42]=5.77, p<.006)$, and a dose $\times$ lever $\times$ treatment effect $(F[4,42]=2.58, p<.05)$. Cocaine in the fluoxetine group had a more pronounced effect when compared with the saline and buproprion groups. Analysis of simple main effects indicated a significant dose $\times$ treatment $\times$ lever interaction (fluoxetine versus buproprion, $(\mathrm{F}[2,42]=4.9, p<.025)$. In all groups, a significant effect of lever was observed $(\mathrm{F}[1,21]=12.1, p<$ $.002)$.

Animals treated chronically with fluoxetine experienced a weight loss significant in comparison to the saline and buproprion treatment groups (Figure 4). Over the eight days that weights were recorded and analyzed, there was a significant treatment effect for weight $(F[2,21]=8.22, p<.002)$. Newman-Keuls analysis of means indicated a significant difference between the fluoxetine group and both the saline and buproprion groups $(p<.05)$.

\section{Experiment 2: The Effect of Intra-Accumbens Dopamine and Serotonin in the Conditioned Reinforcement Test}

Figure 5 shows the effects of intra-accumbens infusion of serotonin and dopamine on responding for conditioned reinforcement. Intra-accumbens serotonin did not selectively potentiate CR responding (Figure 5A). The overall analysis of variance indicated a trend towards a treatment effect that did not quite reach statistical significance $(F[2,18]=2.98, p<.07)$, however when post hoc contrasts were conducted there was a significant difference between saline and $5 \mu \mathrm{g}$ dose treatment $(p<.025)$. This small increase was not selective for the CR lever; in other words, 5-HT tended to increase responding on both levers. In contrast, dopamine dosedependently and selectively potentiated responding for conditioned reinforcement (Figure 5B).

There were significant effects of dose $(\mathrm{F}[2,18]=14.3$, $p<.0002)$, and a dose $\times$ lever interaction $(\mathrm{F}[2,18]=6.1$, $p<.01$ ). Further analysis demonstrated a difference between the saline and $10 \mu \mathrm{g}$ DA contributed to this interaction $(\mathrm{F}[1,18]=8.0, p<.025)$ as well as the difference between the saline and $20 \mu \mathrm{g}$ DA $(\mathrm{F}[1,18]=10.3, p<$ $.01)$. There was additionally, a significant effect of lever $(\mathrm{F}[1,9]=9.3, p<.01)$.

\section{Experiment 3: The Effect of Intra-Accumbens Injections of Serotonin on General Motor Activity}

Serotonin infused into the nucleus accumbens strongly activated motor activity (Figure 6). Overall analysis of the data for the total activity measure revealed a significant effect of dose $(\mathrm{F}[2,14]=7.86, p<.005)$. Post-hoc contrast tests indicated a significant difference between the saline and both the $5 \mu \mathrm{g}$ and $10 \mu \mathrm{g}$ treatments $(p<$ .01). Analysis of the locomotor activity data revealed a significant dose effect $(\mathrm{F}[2,14]=7.02, p<.008)$ and dose $\times$ time interaction between the control animals and those injected with 5-HT $(\mathrm{F}[22,154]=2.43, p<$ .001). Analysis of simple main effects indicated this in-
Figure 5. Effect of intra-accumbens infusion of serotonin or dopamine on responding for a conditioned reinforcer. ${ }^{*} p<.05$; ${ }^{* *} p<.01$, dose effect; ${ }^{\dagger} p<.05{ }^{+\dagger} p<.01$, dose $\times$ lever interaction. \#\# lever effect.
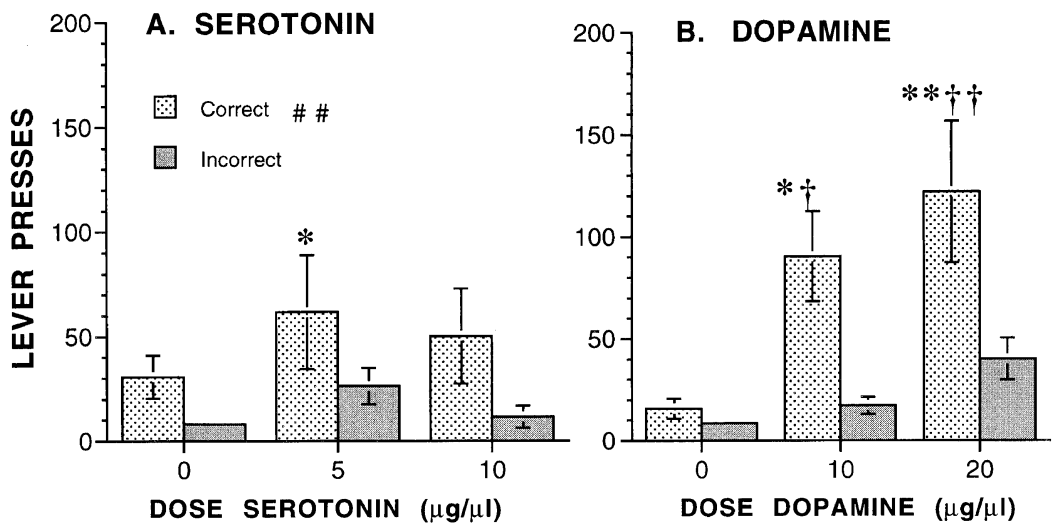

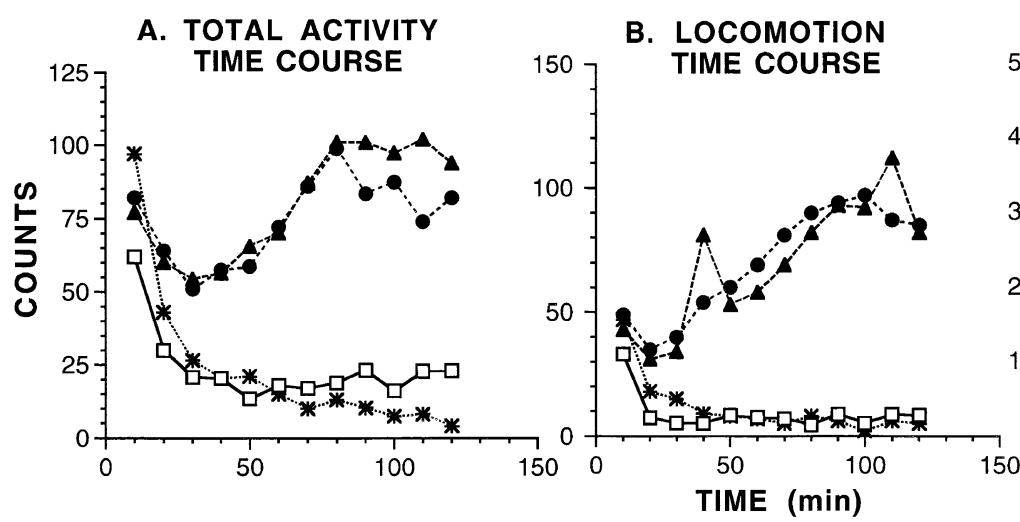

\section{REARING}
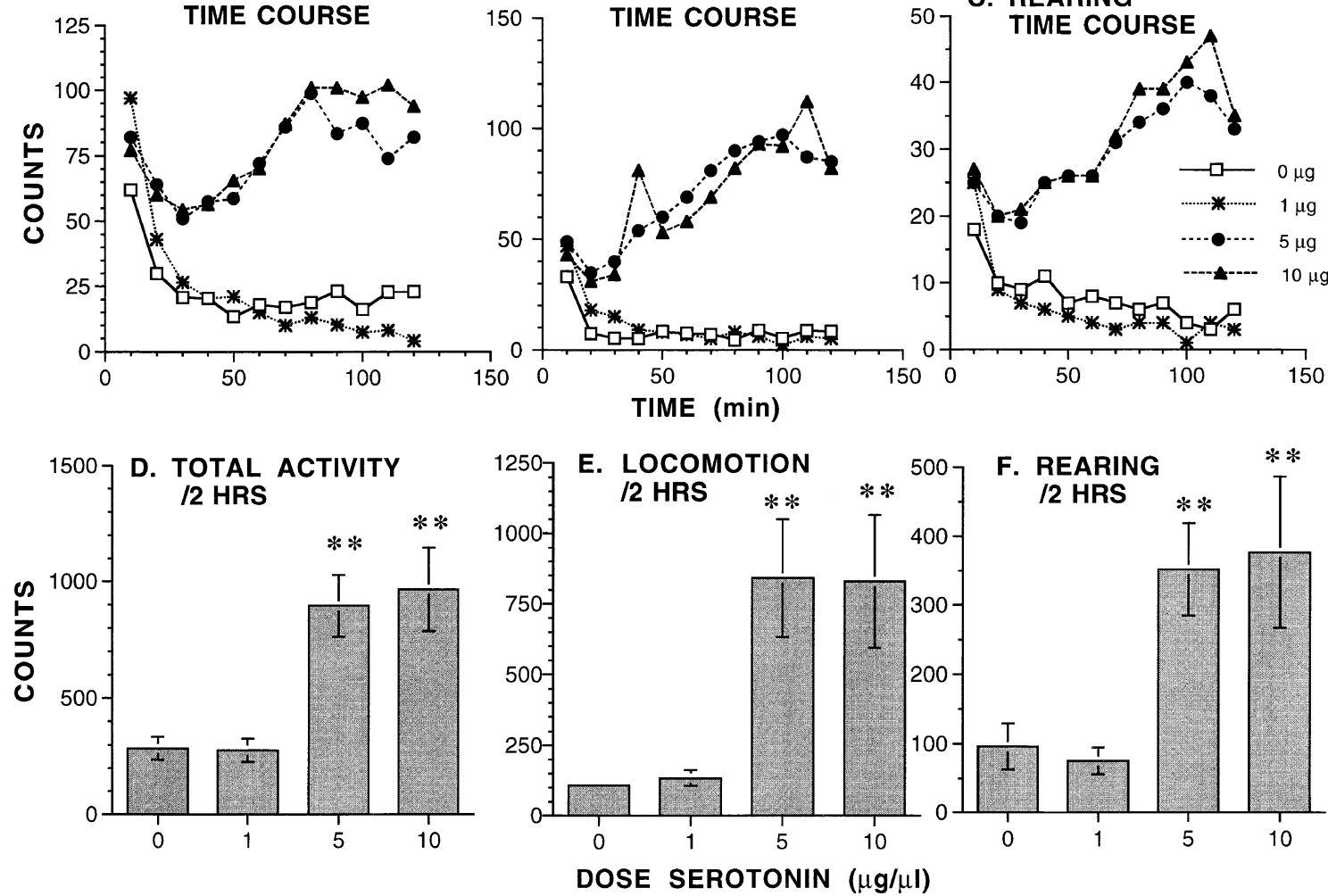

Figure 6. Motor activity following intra-accumbens infusion of serotonin. Top row shows time course of various behaviors and bottom row shows the corresponding totals over the two-hour session. ${ }^{* *} p<.01$, dose effect.

teraction to be due to a difference between saline and the $5 \mu \mathrm{g}$ treatment $(\mathrm{F}[11,154]=2.82, p<.005)$, and between the saline and the $10 \mu \mathrm{g}$ groups $(\mathrm{F}[11,154]=3.7$, $p<.001)$.

In the analysis of the rearing data, a significant effect of dose was observed $(\mathrm{F}[2,14]=4.14, p<.038)$. Post-hoc tests indicated a significant difference between the saline treatment and both the $5 \mu \mathrm{g}$ and $10 \mu \mathrm{g}$ treatments.

\section{Experiment 4: Influence of D1 and D2 Receptor Antagonists on Motor Response to Intra-Accumbens Serotonin}

It can be observed from Figure 7 that the increase in motor activity elicited by intra-accumbens infusion of 5-HT was attenuated by prior administration of DA antagonists. Analysis of the total activity data revealed a significant treatment $\times$ time interaction $(\mathrm{F}[22,176]=$ $1.78, p<.02)$, but no overall treatment effect. Further analysis indicated this interaction to be due to a difference between the saline pretreatment and the $\mathrm{SCH}$ 23390 pretreatment $(\mathrm{F}[11,176]=3.2, p<.001)$. The difference between the saline pretreatment and the raclopride pretreatment, while substantial, did not contribute to this interaction. For locomotor activity data, there were no statistically significant effects, although it ap- peared that neuroleptic pretreatment attenuated the 5-HT response somewhat (overall treatment effect, $p<$ $.08)$. For the rearing data, there also were no significant effects of neuroleptic pretreatment.

\section{DISCUSSION}

The data resulting from these experiments add to the growing literature on serotonin-dopamine interactions. Several general conclusions can be made. First, chronic treatment with the SSRI fluoxetine significantly enhanced acquisition of responding for conditioned reinforcement, suggesting that fluoxetine treatment may potentiate the ability of a reward-associated stimulus to influence behavior. Moreover, the response-potentiating effect of cocaine that is normally observed in control animals in the conditioned reinforcement paradigm is substantially increased in fluoxetine-treated rats. Second, intra-accumbens infusion of serotonin does not selectively enhance reward-related responding (in contrast to dopamine), although it does non-specifically increase lever-pressing and also stimulates motor activity. Serotonergic locomotor activation is partially although not completely blocked by co-administration of DA antagonists. The general interpretation of these data, as discussed below, are 

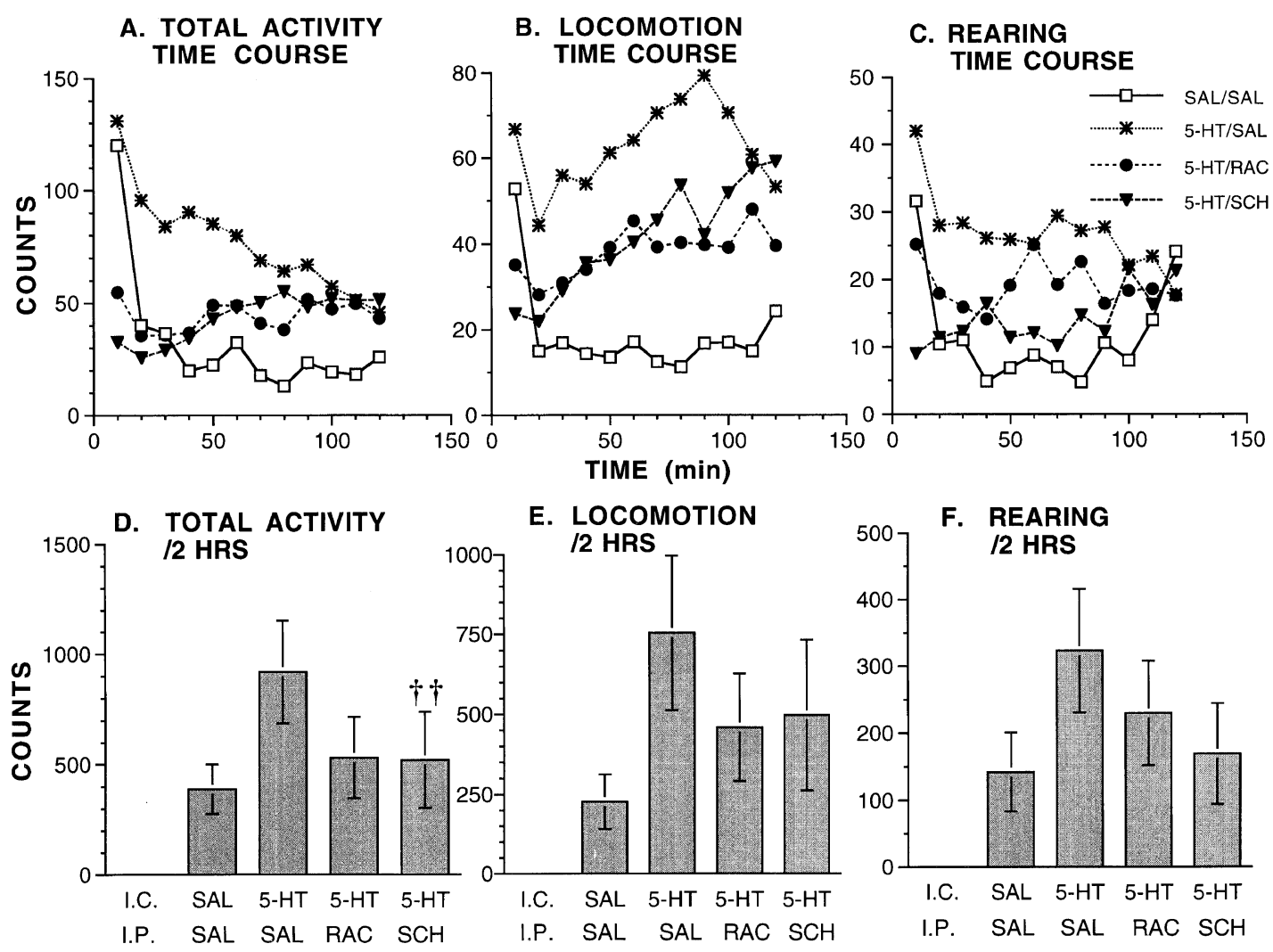

E. LOCOMOTION

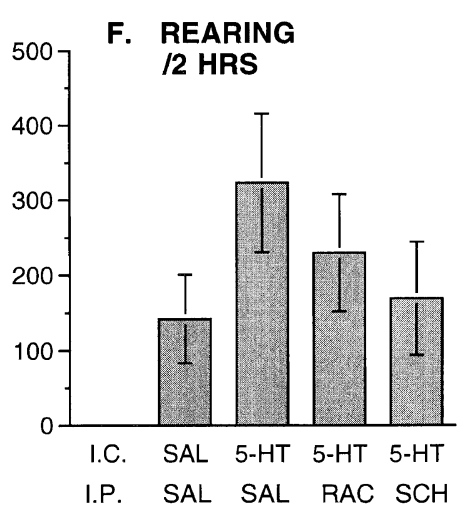

TREATMENT

Figure 7. Influence of pretreatment with DA antagonists on the motor response to intra-accumbens serotonin. Top row shows time course of various behaviors and bottom row shows the corresponding totals over the two hour session. The SAL/SAL group received intra-accumbens saline and i.p. saline; the 5-HT/SAL group received intra-accumbens 5-HT (5 $\mu \mathrm{g})$ and i.p. saline; the 5-HT/RAC group received intra-accumbens 5-HT (5 $\mu \mathrm{g})$ and i.p. raclopride $(1.0 \mathrm{mg} / \mathrm{kg})$; the 5-HT/ SCH group received intra-accumbens 5-HT $(5 \mu \mathrm{g})$ and i.p. SCH $23390(0.1 \mathrm{mg} / \mathrm{kg}) .{ }^{{ }^{+}} p<.01$, treatment $\times$ time interaction with respect to 5-HT/SAL group. I.C., intracerebral; I.P., intraperitoneal.

that increasing serotonergic tone in the accumbens may indirectly influence dopaminergic function.

In the first experiment, chronic treatment with fluoxetine appeared to enhance both baseline responding and the response to cocaine. The conditioned reinforcement test is an established model of an animal's reactivity to a stimulus with reinforcing properties. In this paradigm, the stimulus which had previously been paired with reward (food in a hungry animal) acquires reinforcing properties of its own, as demonstrated by the fact that animals will acquire a new operant response, lever-pressing, reinforced solely by the conditioned stimulus, in the absence of primary reward.

It is well established that rats show a preference for the $\mathrm{CR}$ lever in baseline conditions and that this responding is greatly enhanced by administration of DAreleasing psychostimulants either systemically or in the nucleus accumbens (Kelley and Delfs 1991; Phillips and Fibiger 1990; Robbins 1978; Taylor and Robbins 1984). Thus, it is particularly interesting that chronic treatment enhanced baseline responding, suggesting that treatment with this antidepressant rendered animals more sensitive to a rewarding stimulus. This effect was presumably not due to a general motor activation, since the potentiation was selectively for the CR lever. However, it should be noted that a possible confounding factor is the weight loss experienced by the fluoxetine rats, an effect reported in the literature (Trouvin et al. 1993; Yen and Fuller 1992). Thus it cannot be ruled out that the fluoxetine-treated rats were more sensitive to reward because of their weight loss. Of relevance here is evidence that chronic weight loss indeed is found to enhance the rewarding properties of food, drugs of abuse, and electrical brain stimulation (Cabeza de Vaca and Carr 1998; Cabeza de Vaca et al. 1998). It is unlikely that acute food deprivation alone was responsible for the effect, since the fluoxetine rats were actually given considerably more food than the other two groups, to attempt to prevent their weight loss. However, it is certainly possible that some long-term metabolic factor resulting from chronic weight loss could contribute to the fluoxetine effect. 
The fluoxetine-treated rats also showed enhanced sensitivity to cocaine. This is a particularly interesting finding as it suggests that in some way dopaminergic sensitivity is changed in the SSRI-treated rats. Of course cocaine has multiple effects on transmitter systems, including potent effects on the serotonin system (see Cunningham et al. 1996); however, the enhancing effect of psychostimulants in this paradigm is well-established to be dependent on dopamine (Chu and Kelley 1992; Ranaldi and Beninger 1993). Thus, the potentiation effect in fluoxetine-treated rats is likely to be due to an alteration in dopaminergic pathways. Such an alteration would suggest that chronic fluoxetine has the ability to enhance sensitivity to the rewarding effects of cocaine, which are mediated primarily by dopaminergic neurons. It is also interesting to note that chronic treatment with another SSRI, paroxetine, is also found to facilitate self-stimulation thresholds (Konkle and Bielajew 1999).

Although the neural mechanisms underlying this effect have not yet been determined, a number of studies in the literature provide data for speculation. In one dialysis study of neurochemical effects in rats treated with fluoxetine (in a similar dose range to the present study), no change in baseline extracellular dopamine levels was found, whether the fluoxetine was administered chronically or acutely (Clark et al. 1996). Interestingly though, these authors also found that pretreatment with fluoxetine induced a small increased in cocaine-induced dopamine release in the nucleus accumbens. Another study reported that chronic fluoxetine decreased levels of dopamine in the accumbens (Ichikawa et al. 1998), although these authors also found that such treatment did not affect amphetamine-induced release.

Chronic fluoxetine may influence dopaminergic function indirectly, by changing intracellular signalling pathways. For example, acute fluoxetine has been shown to alter gene expression of Fos, corticotropin-releasing factor (CRF), and the CRF-1 receptor (Torres and Horowitz 1998), and several recent studies reported alterations in transcription factors and neuropeptides with chronic fluoxetine (Caberlotto et al. 1998; Frechilla et al. 1998). Acute fluoxetine is also reported to potentiate amphetamine-induced hyperactivity through inhibition of brain enzymes that metabolize this stimulant (Sills et al. 1999). Overall, however, given how commonly fluoxetine is prescribed, there are remarkably few studies in the literature that examine the effects of such treatment on neurochemical or neuromolecular substrates. Thus, at this juncture we are limited in our speculations.

In contrast to the chronic fluoxetine treatment, chronic buproprion did not enhance baseline nor cocaineinduced responding for conditioned reinforcement. As noted earlier buproprion is also commonly used as an antidepressant, and its actions are thought to be mediated via dopaminergic or noradrenergic effects, although its precise mechanisms of action are not known (Ascher et al. 1995). Like for fluoxetine, there are very few studies of neurochemical or behavioral effects of buproprion. Nevertheless it is interesting that the two treatments were distinguishable in terms of their effect on responding for conditioned reinforcement. Indeed, it appears from the data that buproprion may have actually reduced sensitivity to reward, from perusal of Figures 2 and 3.

Another main finding in these experiments showed a distinction between the effects of 5-HT and dopamine infused into the accumbens on lever-pressing for a rewarding stimulus. As has been demonstrated previously (Cador et al. 1991; Kelley and Delfs 1991) dopamine and indirect DA agonists have strong potentiating effects on responding for conditioned reinforcement. This was replicated in the present experiment. However, serotonin in a similar dose range did not selectively enhance $C R$ lever-pressing, but rather induced a small overall increase in responding (i.e., on both levers). This profile suggests that although both DA and 5-HT can induce a strong motor activating effect when infused into the accumbens, only DA actually has direct effects on responding for reward. However, given that chronic treatment with an SSRI enhances the DA-dependent behavior, we would propose that acute increases in 5-HT do not directly code reward, but rather can modulate its expression through enhanced arousal or motor activity. This notion sits well with current theories that propose a global modulatory role for serotonin in facilitation of motor output (Jacobs and Fornal 1997).

It should be noted that our findings conflict with those of Fletcher and colleagues (Fletcher 1995, 1996; Fletcher et al. 1999). One study showed that treatment with the serotonin-enhancing drugs d-fenfluramine and metergoline actually reduced the response-potentiating effect of intraaccumbens amphetamine in the conditioned reinforcement paradigm (Fletcher 1995). However, once again this was an acute treatment rather than chronic, and so the outcome may be very different. Two further studies indicated that direct infusion of $5-\mathrm{HT}$ or a $5-\mathrm{HT}_{1 \mathrm{~B}}$ agonist also reduced dopamine-dependent effects (Fletcher 1996; Fletcher et al. 1999; also see Layer et al. 1992).

We did not test the direct interaction of 5-HT and DA in the present study, but the results of these latter studies appear to suggest that increased levels of serotonin reduce DA function rather than enhance it, in opposition to our hypothesis. More recently, this group also found that 5,7-DHT lesions of serotonin neurons enhanced responding for a conditioned reinforcer, again suggesting that 5-HT exerts inhibitory tone on DA function (Fletcher et al. 1999). We currently do not have an explanation for this discrepancy, although because of the complexity of the serotonergic system and its receptors, such discrepancies are not uncommon. It may well be that some 5-HT receptors modulate in a facilitatory way whereas other subtypes exert the opposite effect. 
This complexity notwithstanding, a good case can be made from the literature for a facilitatory effect of 5-HT on striatal or accumbens dopamine. Many neurochemical studies demonstrate this relationship (Nurse et al. 1988; Blandina et al. 1988; Yi et al. 1991; Jacocks and Cox 1992; Hallbus et al. 1997; Benloucif and Galloway 1991; Parsons and Justice 1993; Yadid et al. 1994; Yoshimoto et al. 1996). The 5-HT-DA interaction question has been approached in an elegant and novel way by Broderick and Phelix (1997). These authors recorded dopaminergic and serotonergic peaks using in vivo microvoltammetric recording and behavioral analysis. They found that during detection of these neurotransmitters in real time, increases in basal 5-HT release at DA terminal regions were closely associated with increased DA release, and that activity of both amines tracked the time course of an animal's exploration in a novel chamber. This result suggests that the serotonergic system may synergistically interact with the dopaminergic system during states of high arousal of motor activation. In support of this hypothesis, a recent study showed that electrical stimulation of the dorsal raphe nucleus caused increased release of accumbens dopamine (De Deurwaerdere et al. 1996).

In the current experiments, 5-HT infused into the nucleus accumbens caused a pronounced effect on locomotor activity. The duration of this response was likely prolonged by the pretreatment with the MAO inhibitor. We found that this response was partially, although not completely, reduced by co-treatment with DA antagonists. In a related study, we found that direct microinfusion of 5-HT into the ventrolateral striatum induced strong DA-dependent oral stereotypy (Yeghiayan and Kelley 1995). Thus it appears that pharmacologically increased levels of 5-HT are able to mimic DA-like behavior such as enhanced motor activity and oral behavior, perhaps via increasing synaptic levels of dopamine.

While this relationship is beginning to be elucidated, it is not yet clear which 5-HT receptors are involved in these effects, and we have not addressed this question in the current study. However, there is suggestive evidence that both $5-\mathrm{HT}_{1 \mathrm{~B}}$ and $5-\mathrm{HT}_{3}$ receptors may play a role in pro-dopaminergic effects of serotonin. $5-\mathrm{HT}_{1 \mathrm{~B}}$ receptor stimulation enhances dopamine-mediated reinforcement (Parsons et al. 1996), and 5- $\mathrm{HT}_{1 \mathrm{~B}}$ agonists enhance the discriminative properties of cocaine (Callahan and Cunningham 1995, 1997). However, in a dialysis study perfusion with 5-HT caused a ten-fold increase in DA overflow but a $5-\mathrm{HT}_{1 \mathrm{~B} / 1 \mathrm{D}}$ agonist had no effect.

There are many reports of $5-\mathrm{HT}_{3}$-mediated DA release in striatum or accumbens (Carboni et al. 1989; Imperato and Angelucci 1989; Jiang et al. 1990; Chen et al. 1991; McNeish et al. 1993; Tanda et al. 1995; Genova and Hyman 1998; Monti et al. 1999; see also reviews by Hagan et al. 1993; Grant 1995). Thus, the $5-\mathrm{HT}_{3}$ receptor is a good candidate for modulation of dopamine. However, interaction of 5-HT with carrier-mediated mechanisms via the DA transporter have also been well documented (Feuerstein et al. 1986; Schmidt and Black 1989; Yeghiayan et al. 1997; Yi et al. 1991).

In summary, this work has provided additional evidence for serotonin-dopamine interactions in the control of motor and reward-related behavior. Extending our understanding of these effects may have significant implications for progress in the treatment of neuropsychiatric disorders, such as depression and addiction. However, knowledge of the precise molecular and cellular mechanisms governing the interaction awaits further study.

\section{ACKNOWLEDGMENTS}

This work was supported by grant DA04788 from the National Institute on Drug Abuse. D.S.-A. was supported by a Hilldale Undergraduate fellowship awarded by the University of Wisconsin.

\section{REFERENCES}

Ascher JA, Cole JO, Colin JN, Feighner JP, Ferris RM, Fibiger HC, Golden RN, Martin P, Potter WZ, Richelson E (1995): Bupropion: A review of its mechanism of antidepressant activity. J Clin Psychiatry 56:395-401

Beal MF, Martin JB (1985): Topographical dopamine and serotonin distribution and turnover in rat striatum. Brain Res 358:10-15

Benloucif S, Galloway MP (1991): Facilitation of dopamine release in vivo by serotonin agonists: Studies with microdialysis. Eur J Pharmacol 200:1-8

Blandina P, Goldfarb J, Green JP (1988): Activation of a 5-HT3 receptor releases dopamine from rat striatal slice. Eur J Pharmacol 155:349-350

Bonaventure P, Schotte A, Cras P, Leysen JE (1997): Autoradiographic mapping of 5-HT1B- and 5-HT1D receptors in human brain using [3H]alniditan, a new radioligand. Recept Chan 5:225-230

Bouyer JJ, Joh TH, Pickel VM (1984): Ultrastructural localization of tyrosine hydroxylase in rat nucleus accumbens. J Comp Neurol 227:92-103

Broderick PA, Phelix CF (1997): I. Serotonin (5-HT): Within dopamine reward circuits signals open-field behavior. II. Basis for 5-HT-DA interaction in cocaine dysfunctional behavior. Neurosci Biobehav Rev 21:227-260

Caberlotto L, Fuxe K, Rimland JM, Sedvall G, Hurd YL (1998): Regional distribution of neuropeptide Y Y2 receptor messenger RNA in the human post mortem brain. Neuroscience 86:167-178

Cabeza de Vaca S, Carr KD (1998): Food restriction enhances the central rewarding effect of abused drugs. J Neurosci 18:7502-7510

Cabeza de Vaca S, Holiman S, Carr KD (1998): A search for the metabolic signal that sensitizes lateral hypothalamic self-stimulation in food-restricted rats. Physiol Behav 64:251-260 
Cador M, Taylor JR, Robbins TW (1991): Potentiation of the effects of reward-related stimuli by dopaminergicdependent mechanisms in the nucleus accumbens. Psychopharmacology 104:377-385

Callahan PM, Cunningham KA (1995): Modulation of the discriminative stimulus properties of cocaine by 5- HT1B and 5-HT2C receptors. J Pharmacol Exp Ther 274:14141424

Callahan PM, Cunningham KA (1997): Modulation of the discriminative stimulus properties of cocaine: Comparison of the effects of fluoxetine with 5-HT1A and 5-HT1B receptor agonists. Neuropharmacology 36:373-381

Carboni E, Acquas E, Frau R, Di Chiara G (1989): Differential inhibitory effects of a 5-HT3 antagonist on druginduced stimulation of dopamine release. Eur J Pharmacol 164:515-519

Chen JP, van Praag HM, Gardner EL (1991): Activation of 5-HT3 receptor by 1-phenylbiguanide increases dopamine release in the rat nucleus accumbens. Brain Res 543:354-357

Chu B, Kelley AE (1992): Potentiation of reward-related responding by psychostimulant infusion into nucleus accumbens: Role of dopamine receptor subtypes. Psychobiology 20:153-162

Clark RN, Ashby CR Jr, Dewey SL, Ramachandran PV, Strecker RE (1996): Effect of acute and chronic fluoxetine on extracellular dopamine levels in the caudateputamen and nucleus accumbens of rat. Synapse 23:125-131

Cunningham KA, Bradberry $\mathrm{CW}$, Chang AS, Reith ME (1996): The role of serotonin in the actions of psychostimulants: Molecular and pharmacological analyses. Behav Brain Res 73:93-102

Cunningham KA, Callahan PM (1991): Monoamine reuptake inhibitors enhance the discriminative state induced by cocaine in the rat. Psychopharmacology (Berl) 104:177-180

De Deurwaerdere P, Bonhomme N, Lucas G, Le Moal M, Spampinato U (1996): Serotonin enhances striatal dopamine outflow in vivo through dopamine uptake sites. J Neurochem 66:210-215

De Deurwaerdere P, Stinus L, Spampinato U (1998): Opposite change of in vivo dopamine release in the rat nucleus accumbens and striatum that follows electrical stimulation of dorsal raphe nucleus: Role of 5-HT3 receptors. J Neurosci 18:6528-6538

Di Chiara G, Imperato A (1988): Drugs abused by humans preferentially increase synaptic dopamine concentrations in the mesolimbic system of freely moving rats. Proc Natl Acad Sci USA 85:5274-5278

Eberle-Wang K, Mikeladze Z, Uryu K, Chesselet MF (1997): Pattern of expression of the serotonin ${ }_{2 C}$ receptor messenger RNA in the basal ganglia of adult rats. J Comp Neurol 384:233-247

Feuerstein TJ, Hertting G, Lupp A, Neufang B (1986): False labelling of dopaminergic terminals in the rabbit caudate nucleus: Uptake and release of [3H]-5-hydroxytryptamine. Br J Pharmacol 88:677-684

Fletcher PJ (1995): Effects of d-fenfluramine and metergoline on responding for conditioned reward and the response potentiating effect of nucleus accumbens d-amphetamine. Psychopharmacology 118:155-163

Fletcher PJ (1996): Injection of 5-HT into the nucleus accumbens reduces the effects of $d$-amphetamine on responding for conditioned reward. Psychopharmacology 126:62-69

Fletcher PJ, Korth KM, Chambers JW (1999): Selective destruction of brain serotonin neurons by 5,7-dihydroxytryptamine increases responding for a conditioned reward. Psychopharmacology 147(3):291-299

Frechilla D, Otano A, Del Rio J (1998): Effect of chronic antidepressant treatment on transcription factor binding activity in rat hippocampus and frontal cortex. Prog Neuropsychopharmacol Biol Psychiatry 22:787-802

Genova LM, Hyman SE (1998): 5-HT3 receptor activation is required for induction of striatal c-Fos and phosphorylation of ATF-1 by amphetamine. Synapse 30:71-78

Grant KA (1995): The role of 5-HT3 receptors in drug dependence. Drug Alcohol Depend 38:155-171

Hagan RM, Kilpatrick GJ, Tyers MB (1993): Interactions between 5-HT3 receptors and cerebral dopamine function: implications for the treatment of schizophrenia and psychoactive substance abuse. Psychopharmacology (Berl) 112:S68-75

Hallbus M, Magnusson T, Magnusson O (1997): Influence of $5-\mathrm{HT} 1 \mathrm{~B} / 1 \mathrm{D}$ receptors on dopamine release in the guinea pig nucleus accumbens: A microdialysis study. Neurosci Lett 225:57-60

Ichikawa J, Kuroki T, Meltzer HY (1998): Differential effects of chronic imipramine and fluoxetine on basal and amphetamine-induced extracellular dopamine levels in rat nucleus accumbens. Eur J Pharmacol 350:159-164

Imperato A, Angelucci L. (1989): 5-HT3 receptors control dopamine release in the nucleus accumbens of freely moving rats. Neurosci Lett 101:214-217

Jacobs BL, Fornal CA (1997): Serotonin and motor activity. Curr Opin Neurobiol 7:820-825

Jacocks HMD, Cox BM (1992): Serotonin-stimulated release of $[3 \mathrm{H}]$ dopamine via reversal of the dopamine transporter in rat striatum and nucleus accumbens: A comparison with release elicited by potassium, N-methyl-Daspartic acid, glutamic acid and D-amphetamine. J Pharmacol Exp Ther 262: 356-364

Jiang QI, Mosberf HI, Porreca F (1990): Modulation of the potency and efficacy of mumediated antinociception by delta agonists in the mouse. J Pharmacol Exp Ther 254:683-689

Joyce JN, Marshall JF (1987): Quantitative autoradiography of dopamine D-2 sites in rat caudate-putamen: Localization to intrinsic neurons and not to neocortical afferents. Neuroscience 20:773-795

Kelley AE, Delfs JM (1991): Dopamine and conditioned reinforcement. I. Differential effects of amphetamine microinjections into striatal subregions. Psychopharmacology 103:187-196

Kilpatrick GJ, Jones BJ, Tyers MB (1987): Identification and distribution of 5-HT3 receptors in rat brain using radioligand binding. Nature 330:746-748

Kleven MS, Koek W (1998): Discriminative stimulus properties of cocaine: Enhancement by monoamine reuptake blockers. J Pharmacol Exp Ther 284:1015-1025 
Konkle AT, Bielajew C (1999): Feeding and reward interactions from chronic paroxetine treatment. Pharmacol Biochem Behav 63:435-440

Koob GF, Bloom FE (1988): Cellular and molecular mechanisms of drug dependence. Science 242:715-723

Korsgaard S, Gerlach J, Christensson E (1985): Behavioral aspects of serotonin-dopamine interaction in the monkey. Eur J Pharmacol 118:245-252

Layer RT, Uretsky NJ, Wallace LJ (1992): Effect of serotonergic agonists in the nucleus accumbens on d-amphetamine-stimulated locomotion. Life Sci 50:813-820

McNeish CS, Svingos AL, Hitzemann R, Strecker RE (1993): The 5-HT3 antagonist zacopride attenuates cocaineinduced increases in extracellular dopamine in rat nucleus accumbens. Pharmacol Biochem Behav 45:759-763

Monti JM, Ponzoni A, Jantos H, Lagos P, Silveira R, Banchero P (1999): Effects of accumbens m-chlorophenylbiguanide microinjections on sleep and waking in intact and 6-hydroxydopamine-treated rats. Eur J Pharmacol 364:89-98

Nurse B, Russell VA, Taljaard JJ (1988): Characterization of the effects of serotonin on the release of $[3 \mathrm{H}]$ dopamine from rat nucleus accumbens and striatal slices. Neurochem Res 13:403-407

Parsons LH, Justice JB Jr (1993): Perfusate serotonin increases extracellular dopamine in the nucleus accumbens as measured by in vivo microdialysis. Brain Res 606:195-199

Parsons LH, Koob GF, Weiss F (1995): Extracellular serotonin is decreased in the nucleus accumbens during withdrawal from cocaine self-administration. Behav Brain Res 73:225-228

Parsons LH, Weiss F, Koob GF (1996): Serotonin1b receptor stimulation enhances dopamine-mediated reinforcement. Psychopharmacology (Berl) 128:150-160

Paxinos G, Watson C (1998): The Rat Brain in Stereotaxic Coordinates, 4 th ed. Academic Press, New York

Phelix CF, Broderick PA (1995): Light microscopic immunocytochemical evidence of converging serotonin and dopamine terminals in ventrolateral nucleus accumbens. Brain Res Bull 37:37-40

Phillips AG, Fibiger HC (1990): Role of reward and enhancement of conditioned reward in persistence of responding for cocaine. Behav Pharmacol 1:269-282

Pycock CJ, Horton RW, Carter CJ (1978): Interactions of 5-hydroxytryptamine and gamma-aminobutyric acid with dopamine. Adv Biochem Psychopharmacol 19: 323-341

Ranaldi R, Beninger RJ (1993): Dopamine D-1 and D-2 antagonists attenuate amphetamine-produced enhancement of responding for conditioned reward in rats. Psychopharmacology 113:110-118

Robbins TW (1978): The acquisition of responding with conditioned reinforcement: Effects of pipradrol, methylphenidate, d-amphetamine, and nomifensine. Psychopharmacology 58:79-87

Robbins TW, Everitt BJ (1996): Neurobehavioural mechanisms of reward and motivation. Curr Opin Neurobiol 6:228-236

Schmidt CJ, Black CK (1989): The putative 5-HT3 agonist phenylbiguanide induces carrier-mediated release of [3H]dopamine. Eur J Pharmacol 167:309-310

Schultz W (1997): Dopamine neurons and their role in reward mechanisms. Curr Opin Neurobiol 7:191-197

Sills TL, Greenshaw AJ, Baker GB, Fletcher PJ (1999): The potentiating effect of sertraline and fluoxetine on amphetamine-induced locomotor activity is not mediated by serotonin. Psychopharmacology (Berl) 143:426432

Tanda G, Frau R, Di Chiara G (1995): Local 5HT 3 receptors mediate fluoxetine but not desipramine-induced increase of extracellular dopamine in the prefrontal cortex. Psychopharmacology (Berl) 119:15-19

Taylor JR, Robbins TW (1984): Enhanced behavioural control by conditioned reinforcers following microinjections of d-amphetamine into the nucleus accumbens. Psychopharmacology 84:405-412

Torres G, Horowitz JM (1998): Activating properties of cocaine and cocaethylene in a behavioral preparation of Drosophila melanogaster. Synapse 29:148-161

Trouvin JH, Gardier AM, Chanut E, Pages N, Jacquot C (1993): Time course of brain serotonin metabolism after cessation of long-term fluoxetine treatment in the rat. Life Sci 52:L187-L192

Van Bockstaele EJ, Biswas A, Pickel VM (1993): Topography of serotonin neurons in the dorsal raphe nucleus that send axon collaterals to the rat prefrontal cortex and nucleus accumbens. Brain Res 624:188-198

Van Bockstaele EJ, Pickel VM (1993): Ultrastructure of serotonin-immunoreactive terminals in the core and shell of the rat nucleus accumbens: Cellular substrates for interactions with catecholamine afferents. J Comp Neurol 334:603-617

van Praag HM, Kahn RS, Asnis GM, Wetzler S, Brown SL, Bleich A, Korn ML (1987): Denosologization of biological psychiatry or the specificity of 5-HT disturbances in psychiatric disorders. J Affect Disord 13:1-8

Walsh SL, Cunningham KA (1997): Serotonergic mechanisms involved in the discriminative stimulus, reinforcing and subjective effects of cocaine. Psychopharmacology (Berl) 130:41-58

Warbritton JD, Stewart RM, Baldessarini RJ (1978): Decreases locomotor activity and attenuation of amphetamine hyperactivity with intraventricular infusion of serotonin in the rat. Brain Res 143:373-382

Wise RA, Rompré PP (1989): Brain dopamine and reward. Ann Rev Psychol 40:191-225

Yadid G, Pacak K, Kopin IJ, Goldstein DS (1994): Endogenous serotonin stimulates striatal dopamine release in conscious rats. J Pharmacol Exp Ther 270:1158-1165

Yeghiayan SK, Kelley AE (1995): Serotonergic stimulation of the ventrolateral striatum induces orofacial stereotypy. Pharmacol Biochem Behav 52:493-501

Yeghiayan SK, Kelley AE, Kula NS, Campbell A, Baldessarini RJ (1997): Role of dopamine in behavioral effects of serotonin microinjected into rat striatum. Pharmacol Biochem Behav 56:251-259

Yen TT, Fuller RW (1992): Preclinical pharmacology of fluoxetine, a serotonergic drug for weight loss. Am J Clin Nutr 55:177S-180S 
Yi SJ, Gifford AN, Johnson KM (1991): Effect of cocaine and 5 -HT3 receptor antagonists on 5-HT-induced [3H]dopamine release from rat striatal synaptosomes. Eur J Pharmacol 199:185-189

Yoshimoto K, Yayama K, Sorimachi Y, Tani J, Ogata M,
Nishimura A, Yoshida T, Ueda S, Komura S (1996): Possibility of 5-HT3 receptor involvement in alcohol dependence: A microdialysis study of nucleus accumbens dopamine and serotonin release in rats with chronic alcohol consumption. Alcohol Clin Exp Res 20:311A319A 